yet a form of administration which the majority of water undertakers would agree to. "A great deal of education is still required before they will come into line. At present, common action is made possible through regional advisory committees and joint committees. For this reason it has not seemed advisable at present to press the statutory side of any control. If it has to come, it will be later, and it will grow out of the development of the situation indicated, by the continued consideration of those concerned in common problems. A logical ending to development by joint committees is a central one formed from representatives of those committees. There is much more agreement with common working, an inter-connexion of undertakings, with pooling of supplies, but the form of administrative guidance that should be finally instituted has not yet emerged."

\section{Scott Polar Research Institute}

THE building of the Scott Polar Research Institute in Cambridge is to be formally opened by the Chancellor of the University, Mr. Stanley Baldwin, on November 16. The speeches will be delivered in the Senate House, as the building itself is scarcely fitted for the number of people likely to attend the opening ; but it will be inspected afterwards and flood-lit in the evening. The building itself is a memorial to the late Capt. Robert Falcon Scott, whose tragic death with four companions on his return from the south pole in 1912 will still be fresh in the memories of many. The architect was Sir Herbert Baker, and he has succeeded in erecting a building which is both practical for the activities of the Institute and of pleasant appearance. Over the front door is a bust of Capt. Scott by Lady Hilton Young (Lady Scott), and in the forecourt is a symbolic statue by her to the memory of the whole of the polar party. The memorial character is carried into the building in the form of an entrance vestibule with two high domes, painted by Mr. Macdonald Gill with maps of the two polar regions, embellished with the ships and the names of many noted explorers of the past. The three floors accommodate respectively the collections of polar equipment, the library of polar books and maps, and the pictorial collections. On the walls of the attic gallery are hung many of the watercolours painted by Dr. E. A. Wilson, a member of the polar party. There are also four small rooms for the use of the director, staff and research students. After November 16, the building will be open to the public on weekdays, 10 a.m. -4 p.m.

\section{New Building of the Radcliffe Science Library}

THE new building of the Radcliffe Science Library was opened by the Princess Royal on Saturday, November 3. In Convocation on the same day, on the motion of the Master of Pembroke, an address of thanks was presented to Her Royal Highness. The Master of Pembroke gave a brief account of the history of the Library from its foundation by Dr. John Radcliffe, physician to William III and Queen Anne, with its original domicile in the building now called the Camera, its removal to the Museum, and its present status as a department of the Bodleian. The Princess Royal, through the Vice-Chancellor, expressed her gratification in being instrumental in throwing open facilities for scientific study which would be of the highest advantage not only to Oxford but also to the community at large. The new building is an extension of that erected in 1901 adjoining the Museum, and contains two large reading rooms, a three-deck bookstack and two rooms, one for rare books and the other for committees and similar purposes. Part of the first floor reading room has been set apart for mathematical teaching and research pending the erection of a mathematical institute. It is estimated that room will be available for a quarter of a million volumes. The new building, which has cost about $£ 45,000$, is the first stage in a scheme for the reorganisation and extension of the Bodleian Library, towards which the Rockefeller Foundation of New York is contributing three fifths of the total expenditure. At present the Radcliffe Science Library contains a number of books from the Bodleian which will eventually be moved to the main bookstack to be erected in Broad Street, thus setting free ample shelving for the scientific literature of future generations.

\section{The Serial Universe}

ON October 22 and 29, Mr. J. W. Dunne-in whose book, "An Experiment with Time", published a few years ago, evidence of apparent prevision of future events was presented, with a suggested explanation in terms of the character of the time concept-gave two lectures before the Royal College of Science Mathematical and Physical Society on "The Serial Universe". Mr. Dunne described the nature of a 'regress', in which every term except the first is defined by its relation to the preceding and following terms and which therefore produces an infinite series. $\mathrm{He}$ showed that if, in the traditional manner of physics, we regard the scientific description of the world as being necessarily based on the exploration of an objective system with independently existing instruments of observation, we are compelled to employ a concept of time which is regressive, though it has not hitherto been so recognised. Such a concept is adapted to our reasoning powers because we are self-conscious beings, and self-consciousness itself is essentially regressive. The difficulties of modern physics have arisen because attention has been concentrated on the first term only of the temporal regress, which lacks the vital double character of the succeeding terms. Mr. Dunne very acutely applied his ideas to the problems of relativity-attributing the appearance of 'imaginary' time in the Minkowski world to the rotation of the axis of second-term time though $90^{\circ}$ into coincidence with that of first-term time-and to the quantum theory, in which the 'uncertainty' of Heisenberg's principle was found to be regressive and located in the instruments of observation instead of the world observed, which remained determinate. The substance of the lectures, considerably amplified, is to appear almost immediately in book form. 